Tema central

Inaiá Maria Moreira de Carvalho*

\title{
Globalização, metrópoles e crise social no Brasil $^{* *}$
}

\begin{abstract}
This paper discusses the way in which productive restructuration process and Brazilian economy articulation are impacting the main metropolis of the country, where productive activities, wealth and power are concentrated besides the population. In doing so, the text considers how these processes have contributed to a territorial redefinition, as well as to a conformation of new productive and urban architectures and changes in occupational and social conditions. It is also pointed out how these phenomena are taking place in Brazilian metropolitan areas, with the advance of urban segmentation, labor fragility, vulnerability and unemployment, turning these areas into the core of social crisis in Brazil.
\end{abstract}

Key words: Brazil, globalization, metropolis, social crisis.

\section{Resumo}

Este artigo discute como o processo de reestruturação produtiva e a articulação da economia brasileira ao processo de globalização vem impactando sobre as grandes metrópoles do país, onde se concentram as atividades produtivas, a riqueza e o poder, ao lado da população. Para tanto, o texto considera como o processo em apreço tem contribuído para a redefinição de territórios, a conformação de novas arquiteturas produtivas e urbanas e mudanças nas condiçōes ocupacionais e sociais. Assinala, a seguir, como esses fenômenos vem ocorrendo nas áreas metropolitanas brasileiras, com o avanço da segmentação urbana, da precariedade ocupacional, da vulnerabilidade e do desemprego, transformando-as no epicentro da crise social do Brasil.

Palavras chave: Brasil, globalização, metrópoles, crise social. 


\section{Introdução}

$\mathrm{E}$ ste trabalho se propõe a discutir como as transformaçōes dos últimos anos têm atingido as metrópoles brasileiras, afetando as condiçôes ocupacionais, ampliando a vulnerabilidade, degradando as condiçôes de vida de seus habitantes e transformando-as no epicentro da crise social do país.

O estudo das metrópoles, que concentram o aparato produtivo, a riqueza, a população e o poder na grande maioria dos países, adquiriu uma indiscutível relevância na agenda atual da pesquisa urbana, na medida em que o processo de globalização tem contribuído para revitalizar o seu papel e o seu crescimento; tem conformado uma nova geografia $e$ uma arquitetura produtiva que tece redes e nós e qualifica e desqualifica espaços em função de fluxos mundializados, e, também, impactuado sobre a morfologia territorial e social e sobre a organização e funcionamento dessas cidades, sobre a qualidade da vida urbana, as desigualdades e as mobilizações políticas e sociais.

Porisso, estudos internacionais tem ressaltado os vínculos entre o global e o local, valorizados por novas propostas e modelos de gestão urbana, assim como a formação de um sistema mundial de cidades onde algumas mega-aglomeraçôes que adquiriram uma renovada importância como "global cities" funcionariam como uma rede de nós articulados, através dos quais circulariam os mais importantes fluxos de informação, capital e recursos. Tornandose cada vez mais estratégicas para o capital global, elas concentrariam o poder econômico, as sedes das grandes corporações, o controle dos meios de comunicação, os serviços produtivos modernos e a difusão das mensagens dominantes. Isto se daria simultaneamente a uma polarização crescente entre esses espaços e o resto do mundo e ao aumento das diferenciaçôes internas em cada uma das áreas envolvidas.

Autores como Sassen (1991), Reich (1991) e Borja e Castells (1997), por exemplo, analisam as

\footnotetext{
Universidade Federal da Bahia. E-mail: inaiammc@ufba.br

* Recibido el 13 de septiembre de 2005, aprobado el 14 de diciembre de 2005.
}

transformaçōes em curso nessas cidades, com o declínio da atividade industrial, a expansão das atividades financeiras e dos serviços e a mudança do seu papel, tendo como hipótese básica à existência de vínculos estruturais e necessários entre a globalização e a intensificação da dualização social das metrópoles. Com a segmentação do mercado de trabalho, as transformaçōes assinaladas produziriam uma nova estrutura social, marcada pela polarização entre categorias superiores e inferiores da hierarquia social e pela concentração de renda, assim como pela redução das camadas médias ${ }^{1}$. Refletindo-se no plano espacial, esses processos gerariam, também, a dualização das estruturas urbanas.

Investigações realizadas em metrópoles como Paris, Londres, Rio de Janeiro, Buenos Aires ou Santiago do Chile, porém, não confirmam a substituição da estrutura de classes da sociedade industrial por uma polarização entre os mais ricos e os mais pobres nem a dualização do espaço urbano. Evidenciam, antes, uma certa estabilidade das estruturas social e urbana, ao lado de transformaçôes similares como a redução do proletariado industrial, o crescimento do setor terciário e do emprego em serviços ou o empobrecimento de zonas centrais (Ribeiro, $2000 \mathrm{e}$ 2004; De Mattos, 2004; Preteceille, 2003).

Assim, não se pode considerar a existência de uma trajetória única e de tendências universais e inexoráveis para as cidades globais e, muito menos, para as metrópoles de caráter nacional e regional, uma vez que a globalização constitui um processo inacabado e contraditório, com efeitos bastante seletivos sobre os diferentes territórios e dinâmicas que envolvem tanto a homogeneização quanto a diferenciação e a singularização; comandado por forças transnacionais, esse processo não elimina a influência das instituiçōes, atores e decisões políticas nacionais e locais e seus efeitos não deixam de star

\footnotetext{
1 Em trabalho mais recente Sassen (2003) relativiza essa suposição, assinalando que as classes médias não estariam desaparecendo mas que a nova economia urbana contribui menos para a sua expansão que para o reforço das desigualdades existentes e para a emergência de novas desigualdades, ocasionando um crescimento da economia informal e da pobreza e a produção de uma nova marginalidade urbana até mesmo nas metrópoles avançadas, fenômenos antes característicos das sociedades menos desenvolvidas e atribuída às suas "imperfeições",
} 
associados à história e às condições de cada país no momento em que se incorporam mais estreitamente à dinâmica da globalização.

Assinalando como estudos sobre a segregação sócio-espacial têm constatado uma inércia histórica na estrutura hierárquica das grandes cidades e como a mesma não pode ser interpretada como um efeito direto das recentes transformaçōes, Preteicelle (2003, p. 32) ressalta que "ela é, inevitavelmente, uma herança histórica dos movimentos da economia e da sociedade no longo prazo, cristalizada tanto nas estruturas materiais do espaço construído como nas formas sociais da sua valorização simbólica e de apropriação". Reconhecendo esse fato, o presente trabalho começa por se reportar à trajetória e às características do processo de urbanização e metropolização no Brasil, discutindo, a seguir, suas atuais condições.

\section{Urbanização e metropolização no Brasil}

Com uma economia primário-exportadora, baseada na grande propriedade, no trabalho escravo e na produção de alimentos e matérias primas para os centros mais avançados da economia mundial, durante alguns séculos o Brasil foi um país essencialmente rural. Como assinala Faria (1976), em 1920 apenas 16,6\% da população brasileira residia em cidades. Contudo, as próprias exigências e características dessa economia, como o caráter cíclico dos seus produtos de exportação, levando à substituição e deslocamento dos mesmos no espaço geográfico, contribuiu para uma relativa dispersão da população e para uma expansão do sistema de cidades, com a constituição de um arcabouço urbano de certa envergadura.

Em decorrência do próprio crescimento vegetativo da população brasileira, das transformações na agropecuária, intensificação das migrações internas e uma incipiente industrialização, a partir da década de 30 do século passado essa expansão se acelerou. Em 1940 a população urbana já representava $31,2 \%$ dos residentes do país, mas até 1960 ela ainda era inferior a população rural. Duas décadas mais tarde, porém, com um aumento considerável da velocidade do crescimento das cidades, o Brasil tornou-se predominantemente urbano. Em 1980 67,6\% dos brasileiros residiam em centros urbanos e em 2000 esse número chegou a $81,2 \%$, com a sua concentração em um elevado e crescente número de centros de vários tamanhos $\mathrm{e}$ em algumas grandes aglomerações metropolitanas.

Como se sabe, esses fenômenos foram associados a profundas mudanças estruturais, que transformaram a antiga sociedade de base agrária em um país urbano industrial moderno. Alavancados por um estado desenvolvimentista e por um exitoso processo de substituição de importaçōes, do período após a segunda grande guerra até os anos 70, a riqueza e a renda per capita foram multiplicadas por cinco e o produto interno bruto cresceu a uma taxa média de 5,9\% ao ano (Pochmann et al., 2004). Com o avanço da industrialização e dos serviços modernos a estrutura produtiva do país tornou-se mais dinâmica, complexa e diversificada, com uma expansão e diferenciação do mercado de trabalho, das classes e da estrutura social.

Contudo, esse desenvolvimento teve um caráter bastante desigual e excludente, sendo incapaz de efetuar as reformas civilizatórias do capitalismo (como a reforma agrária, a reforma tributária ou uma reforma que universalizasse a proteção social) e de distribuir melhor a riqueza, como ocorreu nos paises onde se constituiu a denominada "sociedade salarial".

Tanto a necessidade de uma certa concentração espacial de infra-estrutura e serviços como a trajetória e o caráter dessa industrialização levaram à sua localização em algumas poucas áreas e centros urbanos, que se tornaram pontos de ancoragem privilegiados das grandes empresas nacionais e multinacionais. Isto estimulou o crescimento das atividades terciárias e da riqueza local atraindo grandes fluxos migratórios para essas cidades, que terminaram por assumir uma configuração metropolitana (com a conurbação de vários municípios) e por concentrar uma proporção bastante elevada da produção, da riqueza e da população nacional.

Como assinalam Moura et al., (2004), em 1970 São Paulo e Rio de Janeiro já conformavam amplas áreas metropolitanas, onde se encontrava, respectivamente, $15,63 \%$ e $13,23 \%$ da população urbana do país. Belém, Belo Horizonte, Curitiba, Fortaleza, Porto Alegre, Recife e Salvador, que desempenhavam 
a função de capitais de Estado, abrigavam outros $16,7 \%$, evidenciando que o fenômeno da metropolização se ampliava, mas sem romper o hiato que distingue esse conjunto de cidades. A industrialização e a constituição de um mercado nacional integrado estabeleceram uma divisão interregional do trabalho que acentuou as desigualdades inter e intra-regionais do Brasil, concentrando o desenvolvimento e a riqueza em uns poucos espaços e metrópoles do centro-sul.

Nas décadas de sessenta e de setenta do século passado o avanço do processo de substituição de importaçóes, políticas de desenvolvimento regional implementadas pelo governo federal e inversōes de grandes empresas estatais promoveram uma maior articulação e complementariedade entre os diversos espaços que compõem a nação brasileira, contribuindo para uma certa descentralização das atividades produtivas e para o crescimento e modernização de algumas áreas, como as grandes capitais nordestinas (Recife, Fortaleza e Salvador), que assumiram uma configuração mais efetivamente metropolitana. Mas essa descentralização foi tímida e vem se revertendo nos últimos anos com o esgotamento do antigo padrão de desenvolvimento e os novos rumos da economia brasileira como será visto a seguir.

Em suma, o caráter desigual e excludente do desenvolvimento brasileiro, que concentrou em alguns poucos centros a produção, a riqueza e o dinamismo, a possibilidade de acesso a vários serviços $\mathrm{e}$ as oportunidades de trabalho e de ascensão social (transformando-as em ilhas de relativa prosperidade em um mar de pobreza e estagnação) atraiu expressivos contingentes de população para os mesmos, levando a constituição de grandes regiōes metropolitanas, agregando municípios vizinhos do pólo em um mesmo complexo de relações.

Com a evolução desse processo, no ano 2000 São Paulo e Rio de Janeiro (consideradas, respectivamente, como a "cidade global" e a gateway city do Brasil) e suas respectivas regiōes abrigavam 28,6 milhōes de pessoas, representando $17 \%$ da população do país, com os pólos metropolitanos concentrando um número maior de habitantes que o conjunto dos demais municípios. Aí se encontrava, também, 18\% da PEA brasileira, $17 \%$ da população ocupada e
$21 \%$ do pessoal ocupado na indústria de transformaçãa ${ }^{2}$. As regióes metropolitanas polarizadas por metrópoles "nacionais" (Fortaleza, Recife, Salvador, Belo Horizonte, Curitiba e Porto Alegre) e pelo Distrito Federal agregavam 23,1 milhōes de habitantes, correspondendo a $13,6 \%$ da população nacional (com uma concentração no município pólo que chega a $80 \%$ em Salvador) e o expressivo estoque de 11,3 milhôes de ocupados, 1,8 milhões deles em atividades industriais (Moura et al., 2004).

Como se sabe, porém, a urbanização e o desenvolvimento brasileiro foram incapazes de assegurar melhores condições de trabalho e de subsistência para o conjunto da população. Apesar da expansão e diversificação da estrutura produtiva e ocupacional das cidades, com a criação de novos empregos em setores como a indústria de transformação, transportes, produção de energia, construção civil, administração pública, finanças, serviços auxiliares à produção e de consumo coletivo, a relação contratual assalariada, regulada por direitos sociais universais, não chegou a se generalizar. A abundância de mão-de-obra e a dimensão do exército de reserva permitiram tanto a compressão salarial como uma coexistência entre o "moderno" e o "tradicional", com a persistência de relaçôes de trabalho precárias em setores como o pequeno comércio, os serviços pessoais ou o trabalho doméstico. Mesmo nas áreas mais dinâmicas, uma reduzida camada de alta renda (com grande poder de consumo e influência social) e camadas médias ampliadas, diversificadas e em ascensão passaram a conviver com o proletariado industrial e terciário e com um vasto, instável e heterogêneo contingente de trabalhadores pobres, de vida incerta e duvidosa.

Ao lado de fatores como a rapidez do processo de urbanização, os interesses do capital imobiliário e a fraca capacidade de regulação e de redistribuição do Estado, isto também contribuiu para a conformação de cidades extremamente desiguais e injustas. Cidades onde as camadas al-

2 Vale ressaltar que a região metropolitana de São Paulo respondia isoladamente por $17,2 \%$ da massa de rendimentos do Brasil, participação equivalente a de todo o grupo de regiões metropolitanas polarizada por metrópoles nacionais, como assinala o trabalho de Moura et al. antes mencionado. 
tas e médias concentravam-se em bairros centrais, com boa disponibilidade de infra-estrutura e serviços, enquanto os trabalhadores tinham que enfrentar a questão da habitação através da autoconstrução de moradias precárias, em periferias distantes e desprovidas tanto de equipamentos como de serviços básicos. Nos anos sessenta do século passado, isto suscitou consideraçōes sobre o caráter "sociopático" dessa urbanização, assim como debates e polêmicas sobre a "marginalidade" para enfocar as dificuldades e "distorçôes" da incorporação dos trabalhadores ao processo produtivo em contextos onde o assalariamento era pouco generalizado, como as cidades do Brasil e da América Latina (Machado da Silva, 2002; Nun, 2004).

Até a década de 70 , porém, o extraordinário desenvolvimento do Brasil, com taxas de crescimento do PIB sempre superiores às do crescimento da PEA, em uma época em que a expansão da produção implicava uma maior demanda de trabalho, ampliou as possibilidades de uma melhor integração social, viabilizada, basicamente, através da migração rural urbana e, notadamente nas cidades de maior porte, de um processo de mobilidade ascendente, intra ou intergeracional. Nessa fase, a elevação do nível de escolaridade da população e a diversificação da estrutura ocupacional propiciaram um aumento das oportunidades de trabalho e de emprego formal (com a proteção e benefícios a ele associados), amortecendo o potencial de conflito e a tensão social e viabilizando a reprodução de uma sociedade extremamente desigual. Da década de 40 até a década de 70, conforme Pochmann (2001) de cada dez postos de trabalho criados apenas dois não eram assalariados e sete tinham um registro formal. Em 1976, segundo Cardoso (2004) os trabalhadores titulares de direitos porque ocupantes de empregos registrados em carteira de trabalho representavam $61 \%$ da força de trabalho do país, que parecia encaminhar-se para a constituição de uma sociedade salarial.

Mas a tendência a uma maior integração através do mercado se reverteu na década de 80 (denominada como a "década perdida") com o esgotamento do modelo de financiamento e do padrão de desenvolvimento até então implementado. Com o agravamento da crise econômica, da crise fiscal do Estado e uma intensa aceleração do processo inflacionário, os caminhos do país foram reorientados, com a implementação de um conjunto de políticas convergentes, recomendadas pelas agências multilaterais. Denominadas como "ajuste estrutural”, "reformas estruturais", ou "reformas orientadas para o mercado", elas envolveram um programa de estabilização, a realização de uma abertura econômica intensa e rápida, a implementação de um amplo programa de privatizaçôes, ênfase nos mecanismos do mercado e uma profunda reformulação do papel do Estado. Não apenas em termos do seu protagonismo econômico e de suas funçóes reguladoras como, também, de suas responsabilidades como provedor de políticas econômicas e sociais.

Foge aos objetivos deste trabalho uma análise do ajuste e da reestruturação produtiva efetuada a partir dos anos noventa, associada a uma inserção passiva e subordinada do país na economia global. Contudo, cabe ressaltar que esses processos agravaram o quadro social do Brasil da década de noventa até o presente, período que vem sendo marcado por: a) baixos níveis de crescimento econômico; b) deterioração das condiçóes de trabalho e de renda da população; c) persistência ou agravamento de desigualdades sociais e espaciais; e d) uma reorientação regressiva das políticas sociais.

Com a desaceleração da produção, baixos níveis de investimento, um grande aumento da dívida interna e externa, dependência dos mercados financeiros e capitais voláteis e vulnerabilidade aos ataques especulativos e às crises internacionais, $o$ Brasil cresceu muito pouco na década de noventa, que também é avaliada como uma segunda década perdida. No início deste milênio o problema persiste, assim como o rompimento do que Cardoso (2004) denomina como a "promessa integradora do mercado formal de trabalho" que marcou o período desenvolvimentista, segundo a qual a economia em crescimento constante incluiria, com o tempo, todos os assalariados em relaçóes de emprego reguladas pelo poder público, garantindo tanto direitos trabalhistas como à representação de interesses em negociações coletivas. Em 2003 o crescimento da economia brasileira chegou a ser 
negativo e em 2005 ele não foi além de 2,3\%, superando apenas o do Haiti ${ }^{3}$.

Com o ajuste e a reestruturação produtiva, a década de noventa também foi marcada por uma expressiva destruição de postos de trabalho, notadamente no setor industrial. Além disso, com a constituição de uma economia de base urbano-industrial no Brasil, há várias décadas que tanto a população como a ocupação na agropecuária vem se reduzindo. $\mathrm{Na}$ medida em que o setor industrial também restringiu o emprego de mão-de-obra, o setor de serviços passou a absorver um maior número de trabalhadores. Mas esse setor é muito heterogêneo, englobando desde os serviços mais modernos até o pequeno comércio, a prestação de serviços pessoais e outras atividades precárias e mal remuneradas do chamado mercado informal, e sua expansão não consegue compensar a destruição de postos que vem se dando nos demais setores.

Conseqüentemente, vem se ampliando o tradicional excedente de mão-de-obra no país, intensificando a seletividade patronal e as dificuldades e desigualdades de acesso aos empregos disponíveis. Isto se traduz em um enorme crescimento do desemprego, na precarização das relações de trabalho e na queda dos rendimentos dos que permanecem ocupados. Discutindo a evolução do mercado de trabalho na década de noventa, Pochmann (2001) e Pochmann et al. (2004), ressalta que se nos anos oitenta $96,1 \%$ das pessoas que se inseriram no mercado de trabalho encontraram uma vaga, nos anos noventa esse percentual se reduziu para $62,5 \%$. Das 13,6 milhões de pessoas que ingressaram no mercado de trabalho nesses últimos anos apenas 8,5 milhões tiveram acesso a algum posto de trabalho, gerando um excedente de 5,1 milhōes de desempregados. Além disso, diversamente do que

\footnotetext{
3 Apesar disto a opção pela política econômica e demais orientaçôes governamentais continua a ser reafirmado, sem maiores perspectivas de transformação. Envolvido em um grave escândalo, o atual Ministro da Fazenda declarou em recente reunião com empresários que a economia brasileira estava em "um céu de brigadeiro", e que a política econômica (tendo o Presidente Lula como fiador) não mudaria com a sua substituição. Quando isto de fato ocorreu, o novo Ministro repetiu essa afirmação. Ademais o Presidente é um forte candidato à reeleição, e seu principal adversário, ligado ao PSDB, tem um perfil bastante conservador, podendo aprofundar ainda mais as atuais orientaçōes.
}

ocorreu nos "anos gloriosos" do capitalismo brasileiro, ou seja, da década de 40 à década de 70 , na década de 90 de cada 10 postos de trabalho criados só dois eram assalariados, porém sem registro formal, o que representou uma profunda e adversa alteração na qualidade da ocupação. Isto porque normalmente $o$ emprego formal representa o que de melhor o capitalismo brasileiro vem oferecendo à sua classe trabalhadora, por ser acompanhado de normas de proteção trabalhista e social.

Com a estagnação da produção e da renda per capita, a escassa geração de empregos e a nova postura do Estado em relação à economia, ao mercado eà sociedade (restringindo suas funçōes reguladoras e sua intermediação nos conflitos de interesses entre capital e trabalho), vem ocorrendo uma enorme precarização e deterioração das relaçôes e condiçõoes de ocupação. Em 2001, conforme informaçōes da PNAD (IBGE, 2003), os empregados representavam apenas $47,8 \%$ da população ocupada no Brasil e boa parte deles não tinha um vínculo formalizado. Com a expansão de atividades precárias e mal remuneradas, como o pequeno comércio, o emprego doméstico e a prestação de serviços pessoais, os trabalhadores por conta própria constituíam 22,3\% daquela população, os trabalhadores domésticos 7,8 , os não remunerados $7,4 \%$, os militares e estatutários 6,8\% e os empregadores 4,2\%. Em 2003 esse quadro praticamente não se alterou. Os empregados representavam novamente $47,8 \%$ do total de ocupados e apenas $62,6 \%$ tinham registro em carteira. Os trabalhadores por conta própria $22,4 \%$, sendo que não mais que $14,8 \%$ deles contribuíam para a previdência social; os trabalhadores domésticos participavam com $7,7 \%$, os não remunerados com 7,1, os militares e estatutários com 6,6 e os empregadores com 4,2\% (IBGE, 2004) ${ }^{4}$.

\footnotetext{
4 Dados do Cadastro Geral de Empregados e Desempregados (CAGED), evidenciam um pequeno crescimento do emprego formal no primeiro semestre de 2005, concentrado em municípios de pequeno e médio porte do interior do país e associado ao crescimento das atividades agropecuárias e agroindustrais. No conjunto das áreas metropolitanas, porém, houve um incremento de apenas $0,47 \%$, com a criação de 48.770 vagas de trabalho, conforme o informativo Em Questão No 334, editado pela Secretaria de Comunicação do Governo e Gestão Estratégica da Presidência da República (2005).
} 
Os baixos rendimentos do trabalho e a persistência de enormes desigualdades constituem outro componente desse quadro. Com o crescimento do desemprego, a inconsistência dos vínculos e a redução dos rendimentos em todos os setores de atividade e para a maioria dos níveis sócioocupacionais, houve redução substantiva da participação dos empregados na renda disponível. Análises de Dedecca (2001) ressaltam como essa participação declinou de 37,5\% em 1991 para $32,8 \%$ em 1999. Se excluídas as contribuições sociais efetivas, esses números passam de $32 \%$ para $26,5 \%$, respectivamente. Em contrapartida, aumentou a participação das empresas, dos impostos e das contribuiçôes, e determinados segmentos sociais também foram privilegiados. Com as altas taxas de juros que vem constituindo um dos pilares da política econômica nos últimos anos, realizando uma significativa transferência de renda do trabalho e da produção para o setor financeiro, por exemplo, os proprietários de títulos financeiros obtiveram lucros extraordinários, o que contribuiu para acentuar a concentração de riqueza e as desigualdades.

\section{Globalização e áreas metropolitanas}

A exclusão e as desigualdades que marcam a trajetória da sociedade e das metrópoles brasileiras vêm sendo acentuadas com a integração do país à dinâmica da globalização, cujos impactos tendem a ser bastante expressivos, em termos sócio-econômicos e espaciais.

Diverso autor tem assinalado como o desenvolvimento espetacular de técnicas que comprimem o tempo e quase eliminam a distância, a crescente financeirização da riqueza e outras características atuais da expansão capitalista, nos marcos da denominada "produção flexível", viabilizaram a constituição de um espaço mundial de acumulação (Santos, 1999; Veltz, 1996; Alonso, 2000; De Mattos, 2004). Constituiu-se um território em rede, radicalmente distinto do anterior, onde cidades, pólos e regiōes transformaram-se em pontos e nós dos fluxos de uma rede imensa e articulada, que se superpõem às fronteiras entre diversos paises transformando-os em espaços nacionais da economia internacional, onde grandes empresas valorizam seus capitais em um número crescente de áreas e atividades, produzindo rápidas mudanças na divisão territorial do trabalho.

Como os fluxos internacionais já não se dirigem preferencialmente para onde os recursos (e principalmente o trabalho) são mais baratos, mas para os paises mais ricos e para os grandes pólos urbanos, produz-se um movimento de diferenciação e homogeneização que torna o território cada vez mais homogêneo em grande escala e fracionado em pequena escala. A hierarquização espacial associada a essa dinâmica (que integra determinadas áreas e segmentos da população enquanto excluem outros) também é acentuada na medida em que as articulações entre os diversos pontos e nós do sistema global tendem a se tornar mais relevantes para o seu desenvolvimento que as antigas relaçōes com suas periferias regionais ou nacionais. Como assinalam Marques e Torres (2000), a geografia e a economia de cada lugar no planeta parecem estar mais atadas que nunca aos fluxos internacionais de pessoas, dinheiro e mercadorias.

Além disso, com a configuração de uma nova arquitetura produtiva que supõe a dispersão e articulação desses nós em um número crescente de lugares, e cujas principais atividades requerem a existência de um múltiplo conjunto de centralidades para manejar e materializar o seu desenvolvimento em escala planetária, a globalização vem contribuindo para revitalizar o papel e o crescimento das grandes aglomerações metropolitanas. Em diferentes escalas, as metrópoles modernas transformamse em sítios estratégicos para as operaçōes econômicas globais dos seus paises (deixando de ser sistemas autocentrados), concentrando as funções de mando, as atividades financeiras e serviços especializados como seguros, consultoria, publicidade ou informática, além da produção imobiliária.

Mas as transformações contemporâneas do capitalismo não têm apenas características espaciais, estando igualmente associadas a um conjunto de medidas para resgatar a taxa de lucro, assegurar a competitividade das empresas em um processo de competição exacerbado e mundializado e viabilizar a dinâmica globalizada do processo de acumulação. Essas medidas envolvem a redução das funçôes e intervençôes reguladoras do Estado, uma enorme 
ênfase nos mecanismos de mercado e o enfraquecimento ou a descontrução de articulaçôes virtuosas entre o mercado, a democracia e a cidadania social que marcaram a sociedade salarial e o fordismo. Para ajustar o trabalhador aos novos requisitos e demandas da produção flexível e do capitalismo globalizado vem ocorrendo uma profunda reestruturação do mundo do trabalho e da própria vida social. Analisadas por autores como Castel (1995), Alonso (2000), Díaz (2004), Darhrendorf (2004), Harvey (1993) e Oliveira (2003), entre tantos outros, essas transformaçōes tem levado a uma desregulamentação, flexibilização e fragmentação do mercado de trabalho, com a descoletivização, reindividualização e precarização dos contratos, a redução de direitos, a expansão da sub-contratação, da ocupação em tempo parcial ou intermitente e de outras formas "atípicas" de emprego, associadas a um extraordinário crescimento do desemprego, enfraquecendo identidades e solidariedades tradicionais e homogêneas de classe e restringindo o poder de reivindicação e representação dos trabalhadores.

Tendências à desindustrialização, à erosão do contrato salarial, à redução das oportunidades de trabalho e remuneraçôes e à restrição de políticas redistribuitivas e sociais tem levado às cidades e metrópoles dos paises centrais condiçôes ocupacionais antes típicas da periferia e atribuídas ao seu atraso, constituindo, nesses paises, o que tem sido considerado como um novo sub-proletariado. Nos centros dominantes do capitalismo, porém, esse subproletariado representa uma minoria dos ocupados (Díaz, 2004). Na União Européia, por exemplo, ele é estimado em 10 a $15 \%$ da população ocupada (Dahrendorf, 2004).

Bem diferente é a situação do Brasil e de outros paises da América Latina, onde (como já foi visto) o esgotamento do padrão de desenvolvimento anterior, o crescimento explosivo do endividamento externo, uma inserção passiva e subordinada na economia global e políticas conservadoras a ela associadas tem conduzido a um baixo crescimento econômico, uma desestruturação e precarização do mercado de trabalho (com a flexibilização da legislaçãa, a redução de direitos e a extensão de contratos ilegais a áreas até então imunes às relações informais do emprego, como a indústria e os serviços modernos), uma exacerbação do desemprego e uma significativa deterioração das condições de vida da população.

Esse fenômeno vem tendo um impacto especial sobre as áreas metropolitanas. Em que pese a sua diversidade, em um país onde as desigualdades inter e intra-regionais são extremamente acentuadas, elas continuam a concentrar a produção e a riqueza, assim como as atividades associadas às exigências do que De Mattos (2004) denomina como "circuito superior da acumulação" e do processo de globalização na economia nacional; ou seja, os serviços auxiliares à produção ou orientados para o consumo de bens e serviços para as famílias de mais alta renda. Paralelamente, porém, crescem os problemas ocupacionais, a vulnerabilidade social e o desemprego, a deficiência de infra-estrutura básica, a carência de habitação e de serviços de consumo coletivo, o número de moradores pobres, as favelas e os cortiços, a violência e a anomia.

Contudo, pesquisas realizadas em várias metrópoles brasileiras não indicam uma dualização da estrutura social urbana, evidenciando principalmente, segundo Ribeiro (2004), uma diminuição dos segmentos modernos e tradicionais do proletariado industrial e um aumento do proletariado terciário, a expansão do sub-proletariado (ambulantes, biscateiros e empregados domésticos) e o crescimento das categorias intermediárias, com mudanças na sua composição interna e o desemprego e empobrecimento de alguns dos seus segmentos. Mas o aumento das desigualdades, da vulnerabilidade e da polarização transparece através de vários indicadores, como o peso dos empregados sem registro formal em carteira, dos ocupados por conta própria, dos empregados domésticos e dos que trabalham sem remuneração no conjunto da população ocupada, que podem ser vistos na tabela que se segue.

Além disso, conforme a PNAD de 2003, 53,6\% dos trabalhadores ocupados no Brasil não contribuíam para a previdência, estando excluídos, portanto, da proteção trabalhista e da seguridade social. Esse percentual chegava a 61,0\% em Belém, 56,1\% em Fortaleza, 50,9\% em Recife e 47,5\% em Salvador. Mesmo nas metrópoles mais desenvolvidas essa frequiência era bastante expressiva, alcançando 
Tabela 1. Distribuição percentual da população ocupada, Brasil e Regiōes Metropolitanas (2003).

\begin{tabular}{|c|c|c|c|c|c|c|c|}
\hline \multirow[t]{2}{*}{ Brasil } & \multicolumn{2}{|c|}{ Empregados } & \multirow{2}{*}{$\begin{array}{c}\text { Militar } \\
\text { estatutário }\end{array}$} & \multirow{2}{*}{$\begin{array}{c}\text { Trabalhadores } \\
\text { domésticos }\end{array}$} & \multirow{2}{*}{$\begin{array}{l}\text { Conta } \\
\text { própria }\end{array}$} & \multirow[t]{2}{*}{ Empregadores } & \multirow{2}{*}{$\begin{array}{c}\text { Não } \\
\text { remunerados }\end{array}$} \\
\hline & Total & \begin{tabular}{|c|} 
C. cart \\
assinada
\end{tabular} & & & & & \\
\hline Brasil & 47,8 & 60,8 & 6,6 & 7,7 & 22,4 & 4,2 & 7,1 \\
\hline Belém & 43,4 & 56,7 & 8,2 & 10,8 & 29,4 & 3,5 & 4,1 \\
\hline Fortaleza & 53,4 & 59,9 & 6,4 & 8,0 & 24,5 & 3,1 & 3,6 \\
\hline Recife & 51,0 & 65,5 & 7,7 & 8,9 & 25,8 & 3,2 & 2,5 \\
\hline Salvador & 52,6 & 67,8 & 6,9 & 10,5 & 24,8 & 3,1 & 1,6 \\
\hline Belo Horizonte & 55,5 & 73,9 & 6,1 & 10,3 & 19,4 & 4,2 & 1,6 \\
\hline Rio de Janeiro & 53,3 & 72,2 & 9,4 & 10,1 & 22,1 & 3,8 & 1,0 \\
\hline São Paulo & 61,5 & 71,9 & 6,6 & 7,9 & 18,5 & 4,5 & 1,1 \\
\hline Curitiba & 55,8 & 76,6 & 6,4 & 8,1 & 20,4 & 4,7 & 2,3 \\
\hline Porto Alegre & 56,2 & 73,0 & 6,7 & 7,5 & 19,2 & 5,4 & 2,4 \\
\hline Distrito Federal & 51,7 & 70,3 & 17,2 & 10,1 & 15,5 & 4,1 & 1,0 \\
\hline
\end{tabular}

Fonte: IBGE/PNAD, Sintese de Indicadores Sociais (2004).

39,7\% em Belo Horizonte, 38,2\% no Rio de Janeiro, 37,5\% em São Paulo, 37,3\% em Curitiba, 37,4\% em Porto Alegre, e 34,9\% no Distrito Federal (IBGE, 2004).

Ao lado da precariedade ocupacional, o desemprego vem assolando as regiōes metropolitanas. Conforme o Censo de 2000, a taxa de desemprego alcançava 17,8\% da PEA em São Paulo, $18,9 \%$ no Rio de Janeiro, 18,6\% em Belo Horizonte, $17,3 \%$ em Brasília, 14,7\% em Curitiba, 17,2\% em Fortaleza, 14,9\% em Porto Alegre, 23,3 em Recife e $25,23 \%$ em Salvador, mostrando porque no conjunto formado pelas regióes metropolitanas globais e nacionais brasileira concentrava-se $40 \%$ dos desempregados do país (Moura et al., 2004). Ademais, o crescimento do desemprego vem sendo agravado pela duração média do tempo de procura de trabalho pelos desempregados e da proporção daqueles há mais de um ano nessa condição. Segundo o DIEESE (2001), a duração média do tempo de procura de trabalho chegava a 11 meses em Belo Horizonte, 15 meses no Distrito Federal, 11 em Porto Alegre, 12 em Salvador, e 10 em São Paulo. O percentual de desempregados em busca de trabalho há mais de um ano se elevava a $21 \%$ em Belo Horizonte, 31,6\% no Distrito Federal, 21,6\% em Porto Alegre, 26,5\% em Salvador e 21,8\% em São Paulo.

Além daqueles segmentos que tradicionalmente já enfrentavam maiores dificuldades para encontrar uma ocupação (como os dotados de menor escolaridade), o desemprego também tem se acentuado entre a força de trabalho na idade mais produtiva (16 a 39 anos), na sua parcela mais ma- dura e experiente ( 40 anos e mais) e até mesmo entre os mais instruídos, ou seja, entre os que possuem o segundo grau completo ou curso superior. Entre os jovens, muitas vezes sem uma qualificação adequada e com uma experiência limitada por sua própria idade, esse problema vem assumindo proporções dramáticas. Nas regiōes metropolitanas brasileiras as taxas de desemprego dos jovens são superiores a $40 \%$ entre os 16 e 17 anos, chegando a 54,1\% em Salvador. Entre os 18 e 24 anos elas vão de 27,5\% em São Paulo a $35,4 \%$ nesta última região metropolitana. Associadas a mudanças nos valores e padrões de organização familiar, como o aumento das separações e do número de famílias chefiadas por mulheres sem a presença do cônjuge, essa retração das oportunidades tem dificultado ou até inviabilizado, inclusive, o recurso às chamadas "estratégias de sobrevivência" (ancoradas na mobilização ocupacional de vários membros do grupo doméstico), que em outras décadas eram utilizadas para a reprodução social dos trabalhadores (Carvalho e Almeida, 2004).

A ampliação da precarização e do desemprego vem sendo paralela a uma queda dos salários reais e a uma significativa redução dos ganhos. Com base no Cadastro Geral de Empregados e Desempregados (CAGED) do Ministério do Trabalho, o DIEESE constatou que o número de trabalhadores formais que recebem não mais que dois salários mínimos ${ }^{5}$ passou de $68 \%$ para $72 \%$ entre 2002 e 2004 , e que empregados afastados

5 O valor atual do salário mínimo no Brasil é de $\mathrm{R} \$ 300,00$, o que corresponde a U\$142,18 mensais. 
Globalização, metrópoles e crise social no Brasil

estão sendo substituídos por outros que ganham até $40 \%$ menos $^{6}$. Em 2003 mais de um terço da população ocupada em Belém, Fortaleza, Recife e Salvador tinha um rendimento médio mensal até um salário mínimo, conforme informaçōes da PNAD (IBGE, 2004). Em Belo Horizonte cerca de um quarto dos ocupados encontrava-se nessa classe de renda, e mesmo nas regiōes metropolitanas do Rio de Janeiro, São Paulo, Curitiba, Porto Alegre e Distrito Federal a freqüência desses trabalhadores não pode ser considerada como desprezível. Já na classe com rendimento médio superior a cinco salários mínimos encontrava-se menos de um décimo dos trabalhadores nas regiōes menos desenvolvidas do Norte e Nordeste do Brasil e entre $12 \%$ a $19,4 \%$ naquelas mais desenvolvidas do Centro-Sul. A situação do Distrito Federal é atípica e se deve à concentração de funcionários dos poderes Executivo, Legislativo e Judiciário em Brasília, com remuneraçóes mais elevadas que a média nacional.

Tabela 2. População ocupada por classes de rendimento médio mensal de todos os trabalhos em salário mínimo, Brasil e Regiōes Metropolitanas (2003).

\begin{tabular}{|c|c|c|c|c|c|c|}
\hline \multirow{2}{*}{$\begin{array}{r}\text { Regiōes } \\
\text { Metropolitanas }\end{array}$} & \multicolumn{6}{|c|}{$\begin{array}{l}\text { População ocupada, } \\
\text { classes de rendimento médio mensal }\end{array}$} \\
\hline & Até $1 / 2$ & Mais de $1 / 2$ a 1 & Mais de 1 a 2 & Mais de 2 a 3 & Mais de 3 a 5 & Mais de 5 \\
\hline Brasil (1) & 19,9 & \begin{tabular}{l|}
17,8 \\
\end{tabular} & 26,0 & 13,0 & 10,2 & 10,3 \\
\hline Belém & 14,1 & 24,8 & 27,3 & 10,3 & 7,4 & 7,5 \\
\hline Fortaleza & 11,9 & 28,7 & 28,8 & 9,5 & 8,4 & 7,4 \\
\hline Recife & 12,9 & 24,9 & 27,8 & 10,4 & 8,5 & 8,0 \\
\hline Salvador & 12,9 & 26,6 & 27,7 & 11,2 & 8,5 & 9,3 \\
\hline Belo Horizonte & 6,9 & 17,4 & 31,7 & 14,3 & 11,5 & 12,0 \\
\hline Rio de Janeiro & 3,0 & 12,1 & 31,1 & 18,0 & 13,8 & 16,4 \\
\hline São Paulo & 2,5 & 8,2 & 26,6 & 20,4 & 17,2 & 19,4 \\
\hline Curitiba & 3,8 & 10,5 & 31,4 & 19,5 & 15,2 & 14,4 \\
\hline Porto Alegre & 4,1 & 10,2 & 30,7 & 18,6 & 14,9 & 15,4 \\
\hline Distrito Federal & 2,6 & 12,2 & 26,3 & 13,9 & 14,1 & 26,3 \\
\hline
\end{tabular}

Fonte: IBGE/PNAD, Sintese de Indicadores Sociais (2004).

(1) Exclusive a população rural de Rondônia, Acre, Amazonas, Roraima, Pará e Amapá.

Nessas circunstâncias, tomando-se como indicador de pobreza uma renda mensal familiar per capita inferior a meio salário mínimo, entre 1991 e 2000 aumentou o número absoluto de moradores pobres nas dez regiōes metropolitanas em discussão, assim como a sua participação relativa em Belém e em São Paulo (Moura et al., 2004). De acordo com a PNAD de 2003, os pobres e indigentes constituíam 30,4\% da população de Belém, 36,6\% de Fortaleza, 31,8\% de Recife e 30,9\% de Salvador. Refletindo, mais uma vez, as desigualdades inter-regionais do país, esses números decresciam para $18,7 \%$ em Belo Horizonte, $16,5 \%$ no Distrito Federal, $13,7 \%$ em Curitiba, 11,6\% no Rio de Janeiro, 11,5\% em São Paulo e 11,2\% em Porto Alegre. Considerando-se, porém, o tamanho da população desses centros, tais percentuais representariam aproximadamente cerca de 108.000 famílias no Distrito Federal, $120 \mathrm{mil}$ em Curitiba, 143 mil em Porto Alegre, 171 mil em

6 Folha de São Paulo, 1 de agosto de 1004, p. B1.
Belém, 273 mil em Belo Horizonte, 305 mil em Salvador, 337 mil em Fortaleza, 342 mil em Recife, 465 mil no Rio de Janeiro e 639 mil em São Paulo. Ademais, com base em dados dos censos de $1991 \mathrm{e}$ 2000, o Atlas do Desenvolvimento Humano no Brasil constatou uma elevação da intensidade da pobreza nesse período em Fortaleza, Salvador, Rio de Janeiro, São Paulo, Curitiba, Porto Alegre e no Distrito Federal, assim como da intensidade ${ }^{7}$ da indigência em todas as dez maiores metrópoles do país.

7 A intensidade da pobreza é definida a partir da renda média dos pobres. Quanto maior a distância entre essa renda média e o valor da linha da pobreza, maior a sua intensidade. Aliado a uma estimativa da proporção de pobres em uma sociedade, esse indicador pode informar a magnitude de recursos que deveriam ser transferidos aos pobres, para que esses tivessem, ao menos, uma renda igual à linha de pobreza. A intensidade da indigência é um indicador similar, referenciado à linha de indigência. 
No caso de São Paulo, tomando-se por base as famílias situadas no topo da distribuição de renda no Brasil, verifica-se que o percentual de famílias mais ricas em relação ao total de famílias aumentou em 100\% entre 1980 e 2000 (Pochmann et al., 2004). Este fenômeno é bem ilustrativo das condiçôes e contradições de São Paulo como metrópole global do país, onde se concentram não apenas a indústria como as atividades terciárias, os serviços mais avançados, a sede das grandes corporaçôes e as melhores oportunidades de ocupação e renda, exacerbando as desigualdades sociais.

Tabela 3. Famílias residentes por classe de rendimento mensal familiar per capita, Brasil e Regiōes Metropolitanas (2003).

\begin{tabular}{|c|c|c|c|c|c|c|c|c|}
\hline \multirow[t]{2}{*}{$\begin{array}{r}\text { Regióes } \\
\text { Metropolitanas }\end{array}$} & \multicolumn{8}{|c|}{$\begin{array}{l}\text { Famílias residentes em domicílios particulares } \\
\text { Renda mensal per capita (em salários mínimos) }\end{array}$} \\
\hline & Até $1 / 4$ & $\begin{array}{l}\text { Mais de } \\
1 / 4 \text { a } 1 / 2\end{array}$ & $\begin{array}{c}\text { Mais de } \\
1 / 2 \text { a } 1\end{array}$ & $\begin{array}{c}\text { Mais de } 1 \\
\text { a } 2\end{array}$ & $\begin{array}{c}\text { Mais de } \\
2 \text { a } 3\end{array}$ & $\begin{array}{c}\text { Mais de } 3 \\
\text { a } 5\end{array}$ & Mais de 5 & Total (1) \\
\hline Brasil (2) & 9,1 & 15,5 & 25,3 & 22,4 & 8,8 & 6,9 & 6,6 & 53.082 .558 \\
\hline Belém & 10,6 & 19,8 & 25,9 & 18,0 & 6,1 & 4,7 & 4,2 & 571.384 \\
\hline Fortaleza & 11,9 & 24,1 & 27,6 & 15,3 & 5,6 & 5,1 & 4,7 & 936.958 \\
\hline Recife & 12,2 & 19,6 & 25,5 & 16,5 & 5,2 & 4,4 & 4,9 & 1.071 .726 \\
\hline Salvador & 10,8 & 20,1 & 24,4 & 17,8 & 7,1 & 5,2 & 6,2 & 987.072 \\
\hline Belo Horizonte & 4,4 & 19,3 & 25,3 & 24,2 & 9,3 & 8,4 & 8,8 & 1.440 .676 \\
\hline Rio de Janeiro & 2,7 & 8,9 & 22,2 & 25,6 & 11,0 & 10,2 & 11,7 & 3.879 .420 \\
\hline São Paulo & 3,2 & 8,3 & 20,0 & 25,2 & 13,0 & 10,0 & 11,5 & 5.817 .921 \\
\hline Curitiba & 3,2 & 10,0 & 22,9 & 28,3 & 12,7 & 10,1 & 9,4 & 928.074 \\
\hline Porto Alegre & 3,0 & 8,2 & 20,5 & 27,9 & 13,2 & 11,6 & 12,2 & 1.305 .193 \\
\hline Distrito Federal & 4,8 & 11,7 & 18,2 & 18,3 & 10,2 & 11,7 & 18,9 & 675.052 \\
\hline
\end{tabular}

Fonte: IBGE/PNAD, Sintese de Indicadores Sociais (2004).

(1) Inclusive as famílias sem declaração e sem rendimento.

(2) Exclusive a população rural de Rondônia, Acre, Amazonas, Roraima, Pará e Amapá.

A dimensão e os efeitos deletérios de pobreza também têm se acentuado em decorrência dos processos de segregação sócio-espacial e segmentação urbana. Como se sabe, a segregação sócio-espacial é uma importante característica das cidades contemporâneas. As regras que organizam o espaço urbano são basicamente padrões de diferenciação social e espacial que indicam como os grupos sociais se relacionam no território. Mas em países como o Brasil essa diferenciação foi intensificada e assumiu um caráter especialmente adverso com o crescimento rápido e acelerado das cidades, as dificuldades de inserção produtiva e a pobreza de amplos segmentos da população urbana, o poder e os interesses do capital imobiliário e uma restrita capacidade de regulação e redistribuição do Estado. Com a conformação do denominado "padrão periférico" os centros urbanos brasileiros tornaram-se extremamente desiguais e segmentados, reservando as áreas centrais (mais aprazíveis e equipadas) para as camadas de alta e média renda e deixando como alternativa para a grande massa de trabalhadores a autoconstrução de moradias em terrenos ocupados ilegalmente ou em loteamentos populares situados em precárias e distantes periferias.

Até a última década de 80 , porém, boa parte desses bairros periféricos se consolidou e melhorou de condição em decorrência do próprio crescimento da cidade, das oportunidades de trabalho e mobilidade social dos seus habitantes e da pressão de fortes movimentos reivindicativos sobre o Estado para a provisão de infra-estrutura e serviços públicos nessas áreas no período da redemocratização. Não é por acaso que, como os dados do Censo de 1991 deixaram patente, se aquela década pode ser considerada como perdida em termos econômicos, o mesmo não ocorre em termos sociais.

Mas isto mudou nos últimos anos, conforme constatado em estudos como os de Bógus e Taschner (1999), Marques e Torrres (2000), Kaztman e Wormald (2002), De Mattos (2004), Ribeiro (2004), Moura et al. (2004), Carvalho (2004), Carvalho, Souza e Pereira (2004) ou Sabatini, Cáceres e Cerda (2004), entre outros. Entre os impactos da abertura e do ajuste vem ocorrendo uma maior 
Globalização, metrópoles e crise social no Brasil

expansão territorial metropolitana, com um menor crescimento demográfico das antigas áreas centrais e um avanço da população para as bordas e para o periurbano; a degradação ou destruição de espaços públicos tradicionais, a emergência de novos padrões da sociabilidade e de consumo e a edificação de artefatos urbanos como super e hiper mercados diversificados ou especializados, shopping centers, complexos de lazer e de cinema (multiplex), edifícios corporativos concebidos com as mais modernas tecnologias ("edifícios inteligentes"), parques temáticos e grandes hotéis de luxo e super luxo para atrair o turismo e grandes eventos, paralelamente a um aumento do nível e da malignidade da segregação.
Ainda que a conformação histórica e as tensões do presente não se encaminhem para uma dualização no conjunto metropolitano, os contornos da pobreza tornam-se cada vez mais delimitados e cristalizados em zonas decadentes das áreas centrais, favelas, loteamentos periféricos e localidades do segundo cinturão. Em moradias precárias e um habitat inadequado aí se aglomera uma população numerosa e densa, acossada pela precariedade ocupacional, o desemprego, e a carência de infra-estrutura e serviços básicos, como ilustra a tabela 4. E, também, mais recentemente, pela perda dos marcos de referência e socialização tradicionais.

Tabela 4. Características da população 40\% mais pobre, Brasil e Regiões Metropolitanas (2003).

\begin{tabular}{|l|c|c|c|}
\hline Brasil & $\begin{array}{c}\text { Domicílios com } \\
\text { Regióes Metropolitanas }\end{array}$ & $\begin{array}{c}\text { Empregados com carteira } \\
\text { de trabalho assinada }\end{array}$ & $\begin{array}{c}\text { Trabalhadores por conta } \\
\text { própria }\end{array}$ \\
\hline Brasil (1) & 37,8 & 30,8 & 31,1 \\
\hline Belém & 24,1 & 25,6 & 39,3 \\
\hline Fortaleza & 42,0 & 30,6 & 29,9 \\
\hline Recife & 28,5 & 26,1 & 36,0 \\
\hline Salvador & 69,7 & 24,5 & 32,7 \\
\hline Belo Horizonte & 78,7 & 23,1 & 22,6 \\
\hline Rio de Janeiro & 74,1 & 22,1 & 24,8 \\
\hline São Paulo & 80,3 & 27,4 & 18,9 \\
\hline Curitiba & 68,7 & 19,8 & 22,3 \\
\hline Porto Alegre & 68,6 & 22,8 & 23,1 \\
\hline Distrito Federal & 79,8 & 19,5 & 19,1 \\
\hline
\end{tabular}

Fonte: IBGE/PNAD, Sintese de Indicadores Sociais (2004).

(1) Exclusive a população rural de Rondônia, Acre, Amazonas, Roraima, Pará e Amapá.

O aumento das desigualdades e a superposição de carências têm contribuído para a degradação dos padrôes de sociabilidade e para o aumento da conflitividade e da violência nessas áreas, inclusive pela maior freqüência de crianças e jovens entre os seus moradores ${ }^{8}$. Entre esses últimos, a contradição entre aspiraçōes de consumo e de realização pessoal elevadas por uma sociedade em que a própria identidade de jovem é associada ao acesso a certos bens, (tênis e roupas "de marca", por exemplo) e a impossibilidade de concretizá-las tem levado, muitas vezes, a uma brutal frustração. Acossados pela pobreza, pelo desemprego e, principalmente, por uma completa ausência de perspectivas, um número

8 Em decorrência do significativo aumento da natalidade na década de oitenta do século passado, na virada do milênio a população brasileira está sendo marcada pela denominada "onda jovem", com a maior participação relativa do contingente de 14 a 24 anos na pirâmide etária da sua história. crescente deles tem se envolvido com pequenos delitos, gangues, seqüestros e tráfico de drogas, contribuindo para o aumento da criminalidade e da violência nas grandes cidades, da qual têm se tornado vítimas principais. Entre 1980 e 2000 a taxa nacional de vítimas de assassinatos na faixa dos 15 a 24 anos, por exemplo, passou de 30 para 52,1 por grupo de 100 mil. São números similares aos de países em guerra, com um predomínio a absoluto de pobres, pretos e pardos e moradores da periferia entre os mortos.

Por outro lado, a concentração da pobreza em áreas homogêneas desassistidas, afastadas e segregadas, também contribui para a sua reprodução. $\mathrm{O}$ local de moradia afeta as condiçôes de vida e a rede de relações sociais de cada pessoa, a qualidade dos serviços públicos aos quais tem acesso e sua probabilidade de conseguir trabalho. Áreas com alta 
concentração de pobreza apresentam uma maior freqüência de atraso escolar, abandono da escola e gravidez precoce. Escolas e postos de saúde aí localizados funcionam mais precariamente, inclusive porque, com o crescimento da violência e a carência de segurança nessas áreas, profissionais como médicos e professores vem tendendo a evitá-las. Redes sociais homogêneas dificultam o acesso ao trabalho e reduzem as possibilidades de mobilidade social, assim como o estigma que atinge certos bairros.

Ademais, o acesso ao transporte é outra questão que não pode ser menosprezada. Além do desgaste a que os moradores das periferias são submetidos pela distância e pela precariedade dos serviços de transporte público, seu custo tem se mostrado crescentemente incompatível com a renda de uma grande parcela da população, restringindo a sua mobilidade a estreitos limites ou obrigando-a a percorrer longas distâncias a pé. Estudo recente do IPEA constatou que, em 2004, 37 milhôes de brasileiros não utilizavam o transporte público por falta de dinheiro para pagar a passagem. Na Região Metropolitana de Salvador, por exemplo, a quarta maior do Brasil, este problema afetava 921.140 pessoas, correspondendo a $35 \%$ da população.

Os problemas assinalados, a expansão territorializada do tráfico de drogas (que se consolida em certas "comunidades"), a disseminação de armas de fogo, o aumento dos conflitos e a carência de inversōes e políticas por parte do Estado, cuja presença nas áreas mais carentes é pautada basicamente pelo controle social e pela repressão, têm levado à conformação de uma cartografia urbana onde existem zonas civilizadas e zonas selvagens. Localidades como a favela da Rocinha, no Rio de Janeiro, o Jardim Ângela, em São Paulo, ou o Subúrbio Ferroviário, em Salvador, adquiriram uma triste notoriedade como exemplos da barbárie, nessa divisão.

\section{Algumas considerações finais}

Como foi visto, o processo de constituição de um espaço mundial de acumulação não elimina a influência das instituições, atores e decisões políticas nacionais e locais e, muito menos, da conformação histórica sobre a qual incidem as suas transformaçōes. Por isso mesmo a evolução recente das metrópoles brasileiras vem sendo marcada principalmente pelo crescimento das desigualdades e da exclusão. $\mathrm{O}$ movimento de desconcentração do desenvolvimento na direção das regiōes menos desenvolvidas do país, que vinha beneficiando metrópoles como Fortaleza, Recife ou Salvador, interrompeu-se na última década de 90. Com a desregulação, a ênfase nos mecanismos de mercado e o minimalismo das políticas de desenvolvimento regional e local, enfatiza-se, agora, a articulação ao exterior daquelas áreas com capacidade de se adaptar e responder mais facilmente aos novos padrôes de organização da produção e aos novos marcos de disputa de mercado, em termos mundiais, fortalecendo a centralização espacial e social das atividades produtivas e da riqueza, com todas as suas conseqüências.

No âmbito das grandes cidades, a concentração dos fluxos dinâmicos da nova economia e de grupos afluentes que consomem bens, serviços, valores e modas de forma voraz e infatigável vêm ampliando igualmente a segmentação e diferenciação. Para atender às demandas das empresas e das camadas de alta renda e estimular o turismo (um dos eixos da estratégia de desenvolvimento de diversas metrópoles brasileiras, a exemplo do Rio de Janeiro, Fortaleza ou Salvador) realizam-se grandes intervenções e investimentos em algumas áreas da cidade, enquanto muitos outros espaços permanecem bastante degradados. Os problemas ocupacionais se agudizam, conforme analisado, e com a crise dos arranjos que garantiam anteriormente um certo equilíbrio, a superposição de carências e o crescimento e consciência da exclusão e da desigualdade, há mudanças nos padrões de sociabilidade e um aumento da conflitividade e da violência. Com o desmanche dos mecanismos que regulavam a sua distribuição no tempo e no espaço e a mescla da violência real com a sua representação na mídia e no imaginário coletivo, constitui-se uma cultura de suspeição e de modo generalizado, que se transforma em um dos princípios organizadores do espaço e da própria vida urbana.

Sob a influência dessa cultura, nas metrópoles e em outras cidades brasileiras a segurança passa a ser vista não mais como um direito público indivisível, e sim como um privilégio dos que podem pagar por ela; ocorre uma negação da atmosfera das ruas e um esvaziamento dos espaços públicos destinados a uma 
Globalização, metrópoles e crise social no Brasil

pluralidade de usuários, marcados pela variedade humana e pelo imprevisto, com a sua substituição por um sistema de espaços seletivos e privativos, protegidos por barreiras materiais e simbólicas, que representam, na expressão de Caldeira (2000), verdadeiros "enclaves fortificados". Nesses enclaves as camadas de alta e média renda buscam formas de moradia, circulação e consumo que lhes permitam conviver entre iguais, isolados e preservados do contacto com a pobreza e da "desordem" e violência urbanas por altos muros, um complexo aparato de segurança e todo um conjunto de regras de evitação, proibição e exclusão. Associando-se a certas demandas do sistema produtivo e a novos valores e padrões de consumo disseminados pela globalização, esse fenômeno tem contribuído para a ocupação de áreas distantes do centro, antes vazias, reforçando tendências à suburbanização, periurbanização e policentrismo que já se esboçavam nas metrópoles; e, também, para a constituição de um arquipélago de ilhas de afluência articuladas entre si mas pouco integradas ao conjunto metropolitano, com a proliferação de condomínios residenciais fechados, prédios corporativos, conjunto empresariais, complexos integrados de cinema (multiplex) ou parques temáticos de lazer, de acesso controlado e socialmente restrito.

Nessas ilhas as classes altas e médias se refugiam, abandonando a esfera pública tradicional das ruas para os pobres, os sem teto e os marginalizados, e se dissolidarizando do destino conjunto da cidade ${ }^{9}$. Daí resulta uma separação física e simbólica que dificulta a sociabilidade, intensifica a fragmentação das identidades coletivas e inferioriza determinados segmentos sociais; muda o caráter do espaço público e esvazia a participação na esfera pública, contribuindo para a persistência desse tipo de urbanidade.

Ademais, com as dificuldades da economia, o crescimento da dívida pública, o ajuste e uma nova

9 Expressando esse tipo de comportamento, informe publicitário de um condomínio residencial fechado à venda na cidade de São Paulo ressaltava as suas virtudes em termos de localização, qualidade da moradia, privacidade e segurança (garantida por uma vasta parafernália), concluindo que o mesmo representava "o lugar ideal para quem quer esquecer a cidade lá fora e aproveitar o seu espaço com toda a tranqüilidade" (Folha de São Paulo, 1 de agosto de 1004, p. B 1.) ênfase no equilíbrio orçamentário, na subsidiariedade estatal e nas forças do mercado, faltam investimentos e políticas públicas para mudar esse quadro. Em decorrência do crescimento dos juros no conjunto da dívida pública e da busca de um superávit primário, as transferências do governo central para os governos locais têm declinado. Com as suas responsabilidades ampliadas e, em muitos casos, também endividados, a capacidade de investimento e de provisão de bens públicos pelos municípios vem encolhendo. Além disso, algumas metrópoles têm deixado as preocupações sociais e redistributivas em absoluto segundo plano, aderindo ao novo modelo de gestão centrado no denominado "empreendorismo urbano". Difundido e incentivado por consultores internacionais e por agências como o Banco Mundial, com o pomposo título de "planejamento estratégico" esse modelo considera o local como a escala geográfica de maior relevância na fase atual do capitalismo e a busca de uma "competitividade urbana" como o objetivo central do "bom governo" das cidades.

Como diverso autor tem assinalado (Harvey, 1993; Vainer, 1998; Fernandes, 2001), essa busca de competitividade supõe uma exploração das vantagens comparativas e a qualificação da cidade para atrair os capitais que circulam no espaço sem fronteiras do mundo globalizado, com a oferta de um ambiente favorável e várias ordens de vantagens e subsídios aos negócios (menores custos de infraestrutura, isenção de impostos, cessão gratuita de terrenos, etc.). A cidade passa a ser pensada como espaço e insumo para a valorização do capital e os gastos públicos direcionados principalmente com esse objetivo, justificando-se essa nova orientação com o retorno a ser obtido em termos de geração de emprego e de outros ganhos coletivos.

Contudo, são as políticas macro-econômicas nacionais que geram maiores impactos sobre o nível agregado de emprego; a margem de manobra da esfera local nessa área é restrita e o retorno e benefícios propagados na maioria dos casos não passam de uma ilusão. Além disso, a disseminação dessas práticas tende a homogeneizar e igualar espaços, generalizando os privilégios oferecidos às empresas e anulando o seu poder de atração. E com a disponibilidade de um número crescente de cidades, gratuidades e benefícios e as facilidades de instalação e transferência 
propiciadas pela produção flexível, as relações do capital com os territórios tendem a ser temporárias e fluídas, levando Milton Santos a se reportar às "empresas circo"... Na prática, esse tipo de política vem produzindo uma redução da capacidade de arrecadação e de provisão de políticas sociais e bens públicos pelo governo municipal, promovendo a valorização imobiliária e contemplando interesses das elites locais enquanto agrava as desigualdades e a segregação, contrapondo-se ao ideário e aos valores de uma cidade mais justa e democrática.

\section{Referências bibliográficas}

Alonso, L.H. (2000). Trabajo y posmodernidad: el empleo débil. Madrid: Editorial Fundamentos.

Bógus, L.M.M. y S.S. Taschner (1999). "São Paulo, velhas desigualdades, novas configuraçōes espaciais". Revista Brasileira de Estudos Urbanos e Regionais, 1: 153-174.

Borja, J. y M. Castells (1997). Local y global. La gestión de las ciudades en la era de la información. Madrid: Taurus.

Caldeira, T.P. do R. (2000). Cidade de muros: crime segregação e cidadania em São Paulo. São Paulo: Ed. 34/EDUSP.

Cardoso, A.M. (2004) A década neoliberale a crise dos sindicatos no Brasil. São Paulo: Boitempo.

Carvalho, I.M.M. de (2004). "Brasil: as cidades e a questão social”. Trabalho apresentado ao Congresso Luso-Afro Brasileiro de Ciências Sociais, 8, Lisboa.

Carvalho, I.M.M. de y P.H. de Almeida (2004). "Familia y protección social em el Brasil contemporâneo”. Estudios Sociológicos, 22, 65: 349-375.

Carvalho, I.M.M. de, Â.G. Souza y G.C. Pereira (2004). "Polarização e segregação sócioespacial em uma metrópole periférica”. Caderno $C R H$, 41: 281-297.

Castel, R. (1995). Les métamorphoses de la question sociale. Paris: Fayard.

Dahrendorf, R. (2004). "El nuevo subproletariado". Díaz, R. (ed.) (2004), Trabajadores precarios. El proletariado del siglo XXI. Madrid: HOAC.

De Mattos, C.A. (2004). "Redes, nodos e cidades: transformação da metrópole latinoamericana”. Ribeiro, L.C. de Q. (org.), Metrópoles. Entre a coesão e a fragmentação, a cooperação e o conflito.
São Paulo: Editora Fundação Perseu Abramo/ Rio de Janeiro: FASE/Observatório das Metrópoles.

Dedecca, C.S. (2001). "Anos 90. A estabilidade com desigualdade”. Encontro Anual da ANPOCS, 25, Caxambu.

Díaz, R. (ed.) (2004). Trabajadores precarios. El proletariado del siglo XXI. Madrid: HOAC.

DIEESE (2001). A situação do trabalho no Brasil. São Paulo: DIEESE.

Faria, V.E. (1976). “O sistema urbano brasileiro: um resumo das características e tendências recentes”. Estudos CEBRAP, 18.

Fernandes, A.C. (2001). "Da reestruturação corporativa à competição entre cidades: lições urbanas sobre os ajustes de interesses globais e locais no capitalismo contemporâneo". Espaço \& Debates, 41: 26-45.

Harvey, D. (1993). A condição pós-moderna. São Paulo: Ediçōes Loyola.

IBGE (2003). Sintese de Indicadores Sociais. (2004). Sintese de Indicadores Sociais.

Kaztman, R. y G. Wormald (coords.) (2002). Trabajo y ciudadanía: los cambiantes rostros de la integración y exclusión social en cuatro áreas metropolitanas de América Latina. Montevideo: Cebra.

Machado da Silva, L.A. (2002). "Da informalidade à empregabilidade (reorganização e dominação no mundo do trabalho)". Caderno CRH, 37: 81-109.

Marques, E. y H. Torres (2000). "São Paulo no contexto do sistema mundial de cidades". Novos Estudos CEBRAP, 56: 139-168.

Moura, R., P. Delgado, M. Deschamps y N.A. Cardoso (2004) "A realidade das áreas metropolitanas e seus desafios na federação brasileira: diagnóstico sócio-econômico e da estrutura de gestão". Trabalho apresentado no Seminário Internacional Desafios das Regióes Metropolitanas em Países Federados, Brasília.

Nun, J. (2004). Marginalidad y exclusión social. Buenos Aires: Fondo de Cultura Económica.

Oliveira, F. de (2003). Crítica à razão dualista/O ornintorrinco. São Paulo: Boitempo.

Pochmann, M. (2001). O emprego na globalização. A nova divisão internacional do trabalho e os caminhos que o Brasil escolheu. São Paulo: Boitempo. 
Globalização, metrópoles e crise social no Brasil

Pochmann, M. et al. (2004). Atlas da exclusão social no Brasil. Vol. 3. São Paulo: Cortez.

Preteceille, E. (2003). “A evolução da segregação social e das desigualdades urbanas: o caso da metrópole parisiense nas últimas décadas". Caderno CRH, 36: 27-48.

Reich, R. (1991). The work of nations. New York: Alfred A. Knopf.

Ribeiro, L.C. de Q. (org.) (2000). O futuro das metrópoles: desigualdades e governabilidade. Rio de Janeiro: Revan: FASE/Observatório das Metrópoles.

(org.) (2004). Metrópoles. En-

tre a coesão e a fragmentação, a cooperação e o conflito. São Paulo: Editora Fundação Perseu Abramo/Rio de Janeiro: FASE/Observatório das Metrópoles.

Sabatini, F., G. Cáceres y J. Cerda (2004).

"Segregação residencial nas principais cidades chilenas: tendências das três últimas décadas e possíveis cursos de ação". Espaço \& Debates, 24, 45: 60-74.

Santos, M. (1999). A natureza do espaço. Técnica e tempo, razão e emoção. São Paulo: HUCITEC.

Sassen, S. (1991). The global city: New York, London, Tokyo. New Jersey: Princeton University Press. (2003). Los espectros de la globalización. Buenos Aires: Fondo de Cultura Económica.

Secretaria de Comunicação do Governo e Gestão Estratégica da Presidência da República (2005). Boletim em Questão, 334 (junho).

Vainer, C.B. (1998). "Cidades, cidadelas e a utopia do reencontro - uma reflexão sobre tolerância e urbanismo". Cadernos IPPUR, 12, 1.

Veltz, P. (1996). Mondialisation, villes et territoires. L'economie d'archipel. Paris: Presses Universitaires de France. 